\title{
Review
}

\section{Harassment in the Field of Medicine: Cultural Barriers to Psychological Safety}

\author{
Fartoon M. Siad, MD, MSc, ${ }^{a}$ and Doreen M. Rabi, MD, MSc ${ }^{\mathrm{b}, \mathrm{c}, \mathrm{d}}$ \\ ${ }^{a}$ Department of Medicine, University of Toronto, Toronto, Ontario, Canada \\ ${ }^{b}$ Department of Medicine, Cumming School of Medicine, University of Calgary, Calgary, Alberta, Canada \\ ${ }^{c}$ Department of Cardiac Science Cumming School of Medicine, University of Calgary, Calgary, Alberta, Canada \\ ${ }^{d}$ Department of Community Health Sciences, Cumming School of Medicine, University of Calgary, Calgary, Alberta, Canada
}

\begin{abstract}
Psychologically safe organizational cultures are inherently inclusive and promote healthy sharing of power and knowledge. These conditions allow innovation to thrive and optimize member performance. Unfortunately, despite its evidence-based nature, the field of medicine continues to struggle with providing safe environments for its members. Several cultural barriers to psychological safety permit endemic harassment. These include having large power gradients, a weak ethical climate, and a number of enabling structural factors that maintain a toxic culture. Moving toward psychological safety will be
\end{abstract}

The concept of "psychological safety" was introduced by Kahn in 1990 and suggests that psychologically safe environments allow individuals to employ themselves fully without fear of negative consequences. Psychologically safe organizations encourage their members to challenge the status quo in order to innovate and evolve their operations or practice. ${ }^{2}$ There is an abundance of evidence to illustrate that those institutions that promote this sort of safety for their members have teams that are more creative, engaged, and effective. Medicine is a profession in which the achievement of psychological safety would seem essential; unfortunately, one could make a reasonable argument that we have all but given up on achieving this goal.

In truth, the medical profession has a problem with overt psychological toxicity. Harassment, intimidation, and discrimination are so common that they have become endemic. A recent survey of German physicians reported that $70 \%$ had experienced workplace harassment. ${ }^{3}$ A report from

Received for publication June 22, 2021. Accepted August 25, 2021.

Ethics Statement: All research reported adhered to the relevant ethical guidelines.

Corresponding author: Dr Doreen Rabi, 3280 Hospital Dr, NW, Calgary, Alberta T2N 4N1, Canada.

E-mail: doreen.rabi@AHS.ca

See page S178 for disclosure information.

\section{RÉSUMÉ}

Les cultures organisationnelles qui favorisent la sécurité psychologique sont intrinsèquement inclusives et favorisent le partage sain du pouvoir et des connaissances. Ces conditions sont un terreau fertile pour l'innovation et l'optimisation du rendement. Malheureusement, bien qu'elle soit par sa nature même fondée sur des données probantes, la médecine est un domaine où l'on peine encore à offrir un environnement sécuritaire. Plusieurs obstacles culturels à la sécurité psychologique permettent un harcèlement endémique, notamment les grands écarts hiérarchiques, un climat éthique déficient et un certain nombre

the National Academy of Sciences in the US reported that over $50 \%$ of women experienced sexual harassment in academic medicine environments. Data collected from 188 medical student respondents across 17 Canadian medical schools via an anonymous online survey found over 800 incidents of sexual harassment including sexist remarks, uninvited touching, stalking, and assault, perpetrated by peers, patients, and faculty. ${ }^{4}$ In Canada, $75 \%$ of resident physicians report experiences of harassment and/or intimidation ${ }^{5}$; this percentage is up $30 \%$ from that of a comparable survey of Canadian medical trainees conducted over a decade ago. ${ }^{6} \mathrm{Few}$ would argue that having three-quarters of our trainees experiencing harassment is simply unacceptable.

In the field of cardiology, and cardiovascular surgery specifically, a global survey of almost 6000 clinicians found their work environments to be highly hostile, with more than half of participants experiencing hostility, women far more (67\%) than men (37\%). Hostility took the form of emotional harassment (29\%), discrimination (30\%), and sexual harassment $(4 \%)$. Higher rates of hostility and discrimination were experienced by women (68\% vs 37\% among men), Black cardiologists ( $53 \%$ vs $43 \%$ among White cardiologists), and North Americans (54\% vs 38\% among South Americans). ${ }^{7}$

Harassment is defined as "repeated and persistent behaviours towards another with the intent to torment, undermine, frustrate or provoke a reaction." ${ }^{8}$ It comprises a number of 
challenging work, as it requires a difficult and complex analysis of the shared value system that enables the status quo. Programs and policies that promote equity, diversity, and inclusion are an important start, but they are likely insufficient on their own to achieve psychological safety. Leadership that models difficult reflection and supports inclusive transformation is the key to a safe culture shift.

behaviours that result in another being demeaned, belittled, humiliated, or embarrassed. An umbrella term, harassment includes behaviours such as intimidation and threats, discrimination (including race- and gender-based), and bullying. Harassment in the field of medicine is common, but the odds of harassment are higher for trainees ${ }^{9}$ (and increase with length of training), women, ${ }^{3,10}$ international medical graduates, ${ }^{11}$ members of the lesbian, gay, bisexual, transgender, queer or questioning, 2-spirit (LGBTQ2+) community, and physicians of colour. ${ }^{12,13}$ The experience of harassment is often longitudinal, and it has been shown to be associated with an erosion of professional confidence, an increased sense of moral distress, and an increase in somatic symptoms, such as anxiety and sleep disturbance. ${ }^{9,14}$ Physicians that experience harassment have a 3-fold increase in the odds of burnout, substance use, and suicidal ideation. ${ }^{10}$ Simulation studies have shown that exposure to bullying reduces team performance and increases the risk of poor clinical decisions; when surveyed, both physicians and nurses believe that harassment in the workplace increases the risk of medical error and poor patient outcomes. ${ }^{15}$

Despite ample evidence of the prevalence of harassment, the literature evaluating effective interventions to disrupt harassment is remarkably sparse. A systematic review of programs to reduce mistreatment among medical learners ${ }^{16}$ identified only 10 evaluative studies of mistreatment prevention programs. The quality of these studies is modest, and only 4 studies actually measured a reduction in experiences of harassment as an outcome (and only one program of the 4 suggested a reduction in events).

Evidence shows that regular exposure to harassment has very harmful effects at both an individual and a health-system level; evidence also indicates that despite people knowing about the prevalence of harassment, the problem is getting worse. How is it possible that healthcare institutions that prioritize the safety of their patients can be so indifferent (or oblivious) to the harm caused by harassment? How is it that institutions committed to continuous quality improvement have been permissive of harassment? How is it that despite knowing the benefits of cultivating psychological safety, we seem unable to achieve it?

The truth is that harassment simply has become a part of our professional experience. The persistence of harassment in the field of medicine reflects a normalization of these disruptive and destructive behaviours within the professional culture. ${ }^{13}$ Organizational culture, or the shared values, beliefs, and principles of its members, has been identified as the single most important predictor of whether harassment is likely to occur. ${ }^{17,18}$ Culture shapes social norms within organizations, de facteurs structurels favorables au maintien d'une culture toxique. Le cheminement vers la sécurité psychologique est une gageure, car il exige une analyse complexe et difficile du système de valeurs partagées qui donne lieu au statu quo. La mise en place de programmes et de politiques axés sur l'équité, la diversité et l'inclusion constitue un premier pas important, mais ne suffira probablement pas à assurer la sécurité psychologique. Un leadership qui s'engage ouvertement dans une réflexion difficile et soutient une transformation inclusive est la clé du passage à une culture sécuritaire.

and an organization's culture will influence how its members interact and behave toward each other; thus, it is a powerful but latent force determining work practices and group dynamics. Unfortunately, given the complexity of how group beliefs and values are determined, organizational culture can be challenging to shift. Examinations of organizational culture in a variety of contexts have identified cultural determinants of harassment. These determinants include the presence of large power gradients, the presence of enabling organizational structures, and weak ethical climates, all of which are present in the field of medicine ${ }^{18}$ (see Fig. 1).

\section{Large Power Gradients}

With attendings, fellows, senior residents, junior residents, and medical students, the field of medicine is unapologetically hierarchical. Hierarchies are defined by large power gradients and competitive individualism and are common in professions that have patriarchal origins or were historically male-dominated. In this cultural structure, people compete with one another for opportunities to gain more influence within the organization. When harassment occurs in such a setting, it is most often perpetrated by those with more power and experienced by those with less. In the arenas of medicine and academia, where people in positions of authority can potentially facilitate or disrupt professional advancement, the risk of harassment is increased. ${ }^{19}$ Fear of reprisal or retribution limits victim or bystander reporting of disruptive behaviour and limits opportunities for persons with power to get feedback to remediate their behaviour. ${ }^{13,20}$

In addition to increasing the risk of interpersonal harassment, hierarchies enable epistemic mistreatment. Epistemic injustices occur when colonial or Eurocentric values and beliefs held at one level of an organization influence how persons are heard or perceived at another level of the organization. ${ }^{21}$ For example, a lack of Indigenous representation among leadership can permit the perpetuation of anti-Indigenous racism and stereotypes. In turn, this situation can facilitate the dismissal of ideas or concerns brought forth by Indigenous trainees or faculty. Gaslighting is a common form of epistemic mistreatment that enables harassment. It occurs when persons use their power to manipulate victims of harassment/abuse to question or doubt their experience of the event(s). The invalidation of traumatic events can have significant negative impacts on mental health and can have lasting negative reputational impacts for victims (with superiors labelling them as disruptive or troublesome). ${ }^{22,23}$ Epistemic mistreatment such as gaslighting is often unconscious but does effectively oppress equity-deserving people, making it a disturbing and tenacious method of preserving hierarchy. 

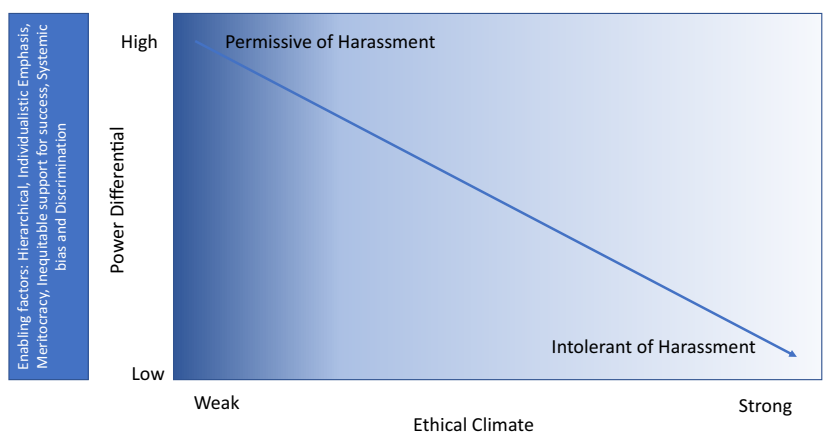

Enabling factors: Non-inclusive leadership, Self-regulation, Fear of Reprisal with Reporting,
Systemic Biases \& Discrimination, Modelling of Harassment

Figure 1. Determinants of psychological safety.

\section{Enabling Organizational Structures}

The academic meritocracy and tenure system sustains the hierarchy through a process of systematic exclusion and concentration of privilege. Although meritocracies are supposed to provide opportunities based on an individual's achievements, talents, or skills, growing evidence indicates that systemic biases and oppressions consistently exclude persons from professional advancement in the field of medicine. ${ }^{24,25}$ Although meritocracies are perceived as awarding opportunity based on merit, if the ability to access or succeed in "meritorious" pursuits is not equitable, then this framework will lead to systematic exclusion. ${ }^{26}$ Tenure is another enabling organizational structure that affords increased professional protections to those at the highest levels of the hierarchy, allowing those with the most power to have the least accountability for their behaviour. ${ }^{27}$

\section{Ineffective Regulation of Professionalism}

Self-regulation as a potential enabling structure is best illustrated by a case example. In 2016, a surgeon in Alberta hung a noose on an operating room door where both Black and Indigenous physicians worked. ${ }^{28}$ This incident was reported to leaders in administration and to the provincial regulatory body, the College of Physicians and Surgeons of Alberta (CPSA). In 2020, a tribunal determined that although the noose could be seen as a symbol that could intimidate and threaten the operating room staff, the tribunal did not recognize this as race-based harassment or intimidation, citing insufficient evidence to determine that the perpetrator was motivated by racism. The tribunal did find the perpetrator guilty of unprofessional behaviour.

Medical professionalism is self-regulated, and although the effectiveness of this sort of governance for physicians has been debated, ${ }^{29,30}$ for better or worse, we are supposed to hold each other to account when unprofessional acts occur. The hierarchical organization and the meritocracy both contribute to an unhealthy concentration of power and likely to the belief that medical leaders are well equipped to regulate their peers. However, as this case illustrates, self-regulation has several limitations when it comes to addressing and preventing harassment. First, professionalism is defined by nonrepresentative physician leadership, who may not have insight into how equity-deserving populations experience harassment. ${ }^{31}$ In the case presented, the determination of whether harassment occurred was centered on the motivation of the harasser instead of the experience of the harassed. This case reveals large institutional knowledge gaps regarding the influence of systemic racism on staff behaviour. Whenever systemic and/or internalized racism exists, whether a person was consciously racist is irrelevant; what is relevant is whether only racialized persons would be harmed, threatened, or intimidated by an action. Without respectful inclusion and representation, our frameworks of accountability will lead to compounded harm instead of justice, as they did in this particular case.

A second reason a lack of representation undermines effective accountability is that several harassment behaviours are subtle, and without standards of practice that define harassment, harmful actions may not be recognized. ${ }^{30,32}$ The patriarchal and colonial history of the field of medicine has largely been internalized by the prevailing medical culture, such that many conventions we have (what we have defined as preferred modes of dress, communication, or management style) may not be consistent with the traditions of equitydeserving people (particularly those that have experienced the harms of colonial oppression). The pressure to conform to these conventions is considerable, and the act of conforming is called "code-switching." ${ }^{33}$ Code-switching is invisible to those that create the expectation of conformity, and thus, a person with power will be oblivious to the mental and emotional toll this process takes on equity-deserving people. When senior colleagues "coach" equity-deserving colleagues on these professional behaviours, this is harassment, but such behaviour will be seen as well-intended feedback by the harasser (and by traditional regulatory bodies).

Lastly, experiences of harassment may not have corroborating physical evidence or witnesses, and in the absence of corroborating evidence or testimony, regulatory bodies tend to dismiss charges of misconduct. ${ }^{34}$ The dismissal and diminishing of the event ("I am sure you misunderstood-that colleague is very well respected") not only is disrespectful, but also once again reveals a lack of knowledge regarding the prevalence and nature of harassment in our profession.

\section{Weak Ethical Climate}

The ethical climate of an organization is the shared perception of its members toward its own practices. ${ }^{27,35} \mathrm{An}$ organization with a weak ethical environment is one in which inappropriate actions are left unchecked, and there is a perception that the consequences for inappropriate behaviour are minimal or nonexistent. Leaving aside the ethical climate of our clinical work, the climate of our intra-professional environment is weak.

Despite the high prevalence of harassment in the field of medicine, formal reporting of harassment is rare. A survey conducted by the American Association of Medical Colleges suggests that just over $70 \%$ of harassment experiences are not reported. ${ }^{36}$ Surveys of medical staff and trainees reveal that harassment goes unreported because reporting is perceived to be too onerous or too dangerous and as being ultimately potentially more harmful than the initial harassment experience. ${ }^{13,37}$ There is also a widely held belief within the field of medicine that dehumanizing behaviour is to be expected, given the high-stress nature of the profession, and an inability 


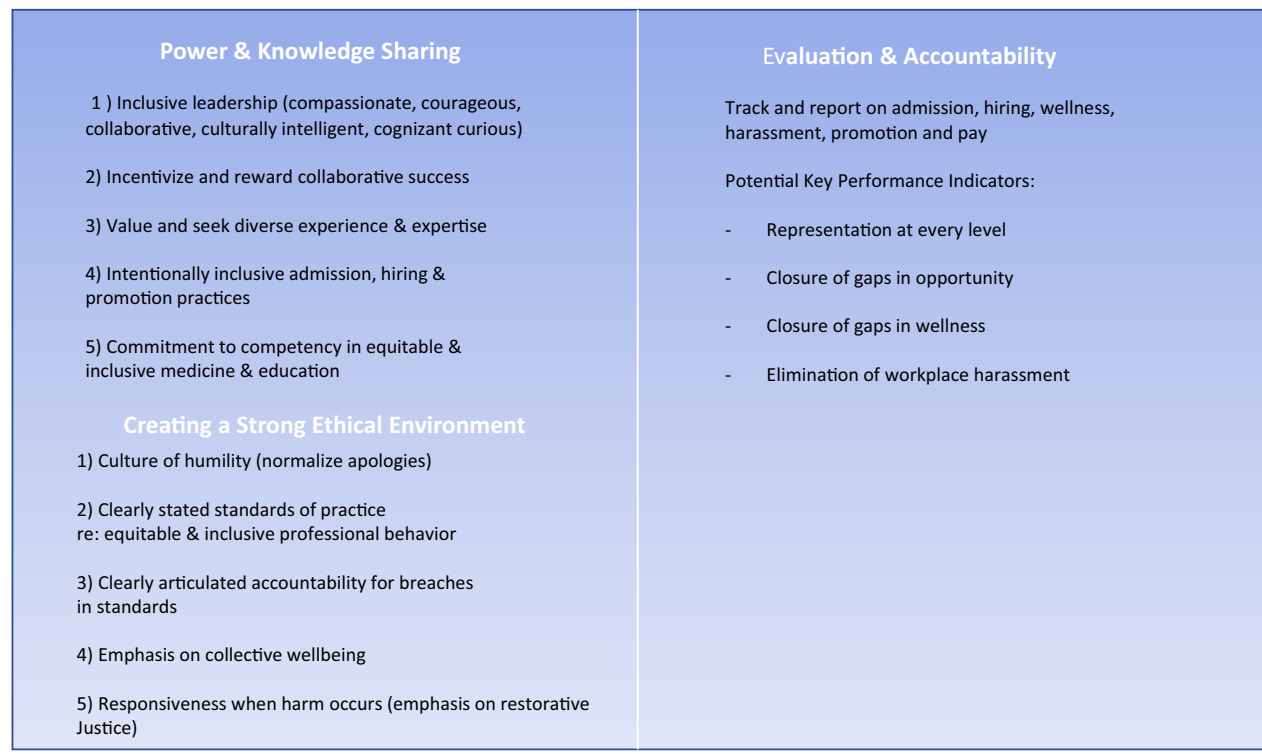

Figure 2. Creating psychologically safe environments.

to tolerate this behaviour is a sign of weakness or a lack of professional "fit." 20,37 Others have reported that the culture of self-sacrifice in the field of medicine facilitates the acceptance of harassment as a normal part of the professional journey (albeit a significant barrier to personal wellness). ${ }^{38,39}$ Similarly, physician and resident wellness programs that emphasize resilience without addressing the harassment problem can tacitly validate the view that the field of medicine is a rough business. Authentic promotion of health and safety in our profession is clearly important; however, if organizations focus on individual resilience training without addressing prevalent, system-enabled harassment, resilience training may inadvertently contribute to normalizing mistreatment, and entrenching the weak ethical climate. ${ }^{40}$

Concerning evidence indicates that harassment is being modelled and implicitly taught to physicians. This socialization of learners to participate in harassment has come to be known as the "hidden curriculum" of the field of medicine. ${ }^{41}$ Hopkins and colleagues ${ }^{42}$ reviewed reports of harassment perpetuated by faculty and trainees at the Stanford Hospitals and Clinics. This review demonstrated that the medical specialties with the highest rates of harassment also had the highest rates of harassment events perpetrated by trainees. In other words, harassment events perpetrated by faculty or trainees were clustered within speciality groups, and faculty harassment events were very highly correlated with trainee harassment events (Spearman's $R=0.90, P<0.001$ ). Although causal inferences cannot be drawn, these data strongly suggest that faculty are modelling harassment to learners. ${ }^{42}$

\section{Moving Toward a Psychologically Safe Practice of Medicine}

Psychologically safe environments limit opportunities for harassment to occur. Cultivating such environments requires that 4 conditions be present, including the following: (i) a feeling of inclusion; (ii) safe learning experiences; (iii) an equitable ability to contribute; and (iv) support for challenging the status quo and demonstrating curiosity. ${ }^{2}$ The achievement of these conditions allows for a shift from individualism to collectivism and places an emphasis on shared humanity. The presence of these factors heightens our ability to see the strengths of others (rather than weaknesses) and opportunities (rather than threats) when presented with differing views. Achieving psychological safety not only creates positive professional experiences due to a strong sense of belonging, but also encourages innovation, as people feel safe to explore new ideas and challenge conventional thinking. Cultivating the conditions for psychological safety is possible but requires a critical examination of almost every aspect of our profession and a collective will to do this important but difficult work.

A number of programs and policies are available for organizations to adopt to promote psychological safety (see Fig. 2). These include the following: targeted recruitment of equity-deserving learners and faculty; adoption of antioppressive standards of practice and codes of conduct; training in implicit bias and bystander intervention; revision of curricula to be centered on equity; development of competency in health equity; and the adoption of restorative justice models of accountability. However, the success of these programs will be limited if there is not a collective desire to shift the culture.

To move things forward, the fundamental value system needs to be dismantled and replaced with a system that values inclusion and safety. To dismantle the current system, there must be a willingness to reflect with honesty and humility on how the field of medicine has created a culture that permits ongoing harm to colleagues, and by extension, patients.

Several Canadian medical schools, professional organizations, and regulatory bodies have made public commitments and created internal programs to promote equity, diversity, and inclusion (EDI) - which is an important step in the right 
direction. $^{8,43-45}$ To be successful, EDI initiatives need to simultaneously promote diversity and create synergies-between new members from previously underrepresented groups and previously majority members-that encourage mutual success and sharing of power. Also important is that the work of championing EDI should not fall on the shoulders of equity-deserving people. Asking people who have been harmed by a culture to fix that culture is completely inappropriate, but it is so common that this offloading of difficult (and often non-meritorious) work has been termed the "minority tax." ${ }^{46}$ Success in achieving EDI and promoting psychological safety requires highly effective, inclusive leadership, with clear policies and standards in place that enable an environment in which calling out injustices across ranks becomes the norm. Although culture is the most significant determinant of harassment, leadership is the greatest determinant of culture.

\section{Conclusion}

Cultivating a culture of psychological safety in the field of medicine is critically important. The rates of harassment in our profession are unacceptably high and must be addressed. The failure to create safe environments severely limits our potential as a profession and leads to unnecessary harm to our colleagues, and in all likelihood, our patients. Cultivating safe environments requires an inclusive transformation of the field of medicine, which is daunting, but absolutely possible and necessary.

\section{Funding Sources}

The authors have no funding sources to declare.

\section{Disclosures}

The authors have no conflicts of interest to disclose.

\section{References}

1. Kahn WA. Psychological conditions of personal engagement and disengagement at work. Acad Manag J 1990;33:33.

2. Clark TR. The 4 Stages of Psychological Safety: Defining the Path to Inclusion and Innovation. San Francisco: Berrett-Koehler, 2020.

3. Jenner S, Djermester P, Prugl J, Kurmeyer C, Oertelt-Prigione S. Prevalence of sexual harassment in academic medicine. JAMA Intern Med 2019;179:108-11.

4. Phillips SP, Webber J, Imbeau S, et al. Sexual harassment of Canadian medical students: a national survey. EClinicalMedicine 2019;7:15-20.

5. Vogel L. Canadian medical residents report pervasive harassment, crushing workloads. CMAJ 2018;190:E1371.

6. Cohen JS, Leung Y, Fahey M, et al. The happy docs study: a Canadian Association of Internes and Residents well-being survey examining resident physician health and satisfaction within and outside of residency training in Canada. BMC Res Notes 2008;1:105.

7. Sharma G, Douglas PS, Hayes SN, et al. Global prevalence and impact of hostility, discrimination, and harassment in the cardiology workplace. J Am Coll Cardiol 2021;77:2398-409.
8. Government of Canada. Equity, diversity and inclusion: dimensions. Available at: https://www.nserc-crsng.gc.ca/NSERC-CRSNG/EDI-EDI/ Dimensions_Dimensions_eng.asp. Accessed June 18, 2021.

9. Pololi LH, Brennan RT, Civian JT, et al. Us, too. Sexual harassment within academic medicine in the United States. Am J Med 2020;133: 245-8.

10. Hu YY, Ellis RJ, Hewitt DB, et al. Discrimination, abuse, harassment, and burnout in surgical residency training. N Engl J Med 2019;381: 1741-52.

11. Ayyala MS, Rios R, Wright SM. Perceived bullying among internal medicine residents. JAMA 2019;322:576-8.

12. Bahji A, Altomare J. Prevalence of intimidation, harassment, and discrimination among resident physicians: a systematic review and metaanalysis. Can Med Educ J 2020;11:e97-123.

13. Broad J, Matheson M, Verrall F, et al. Discrimination, harassment and non-reporting in UK medical education. Med Educ 2018;52:414-26.

14. Szafran O, Woloschuk W, Torti JMI, Palacios Mackay MF. Intimidation, harassment, and discrimination during family medicine residency training: a mixed methods study. BMC Med Educ 2021;21:173.

15. Riskin A, Erez A, Foulk TA, et al. The impact of rudeness on medical team performance: a randomized trial. Pediatrics 2015;136:487-95.

16. Mazer LM, Bereknyei Merrell S, et al. Assessment of programs aimed to decrease or prevent mistreatment of medical trainees. JAMA Netw Open 2018;1:e180870.

17. Knapp D, Faley RH, Ekeberg SE, Dubois CL. Determinants of target responses to sexual harassment: a conceptual framework. Acad Manag Rev 1997;22:42.

18. Willness CR, Steel P, Lee K. A meta-analysis of the antecedents and consequences of workplace sexual harassment. Personnel Psychol $2007 ; 60: 127-62$.

19. Cantor DFB, Chibnall SH, Bruce C, et al. Report on the AAU Campus Climate Survey on Sexual Assault and Sexual Misconduct. Rockville: Association of American Universities, 2015.

20. Colenbrander L, Causer L, Haire B. 'If you can't make it, you're not tough enough to do medicine': a qualitative study of Sydney-based medical students' experiences of bullying and harassment in clinical settings. BMC Med Educ 2020;20:86.

21. Kubota R. Confronting epistemolgical racism, decolonizing scholary knowledge: race and gender in applied linguistics. Appl Ling 2020;41: 712-32.

22. Sweet PL. The sociology of gaslighting. Am Sociol Rev 2019;84:851-75.

23. Fraser $S$. The toxic power dynamics of gaslighting in medicine. Can Fam Phys 2021;67:2.

24. Cropsey KL, Masho SW, Shiang R, et al. Why do faculty leave? Reasons for attrition of women and minority faculty from a medical school: fouryear results. J Womens Health (Larchmt) 2008;17:1111-8.

25. Golden SH. The perils of intersectionality: racial and sexual harassment in medicine. J Clin Invest 2019;129:3465-7.

26. Bandiera G, Maniate J, Hanson MD, Woods N, Hodges B. Access and selection: Canadian perspectives on who will be good doctors and how to identify them. Acad Med 2015;90:946-52.

27. Tenbrunsel AE, Rees MR, Diekmann KA. Sexual harassment in academia: ethical climates and bounded ethicality. Annu Rev Psychol 2018;70:345-70. 
28. College of Physicians and Surgeons of Alberta. Professional conduct report. Available at: https://cpsa.ca/news/professional-conduct-report/. Accessed May 26, 2021.

29. Bauchner H, Fontanarosa PB, Thompson AE. Professionalism, governance, and self-regulation of medicine. JAMA 2015;313:1831-6.

30. Marcovitch H. Governance and professionalism in medicine: a UK perspective. JAMA 2015;313:1823-4.

31. Jagsi R, Griffith KA, Jones R, et al. Sexual harassment and discrimination experiences of academic medical faculty. JAMA 2016;315:2120-1.

32. Torres MB, Salles A, Cochran A. Recognizing and reacting to microaggressions in medicine and surgery. JAMA Surg 2019;154:868-72.

33. Wood NI. Departing from doctor-speak: a perspective on code-switching in the medical setting. J Gen Intern Med 2019;34:464-6.

34. AbuDagga A, Carome M, Wolfe SM. Time to end physician sexual abuse of patients: calling the U.S. medical community to action. J Gen Intern Med 2019;34:1330-3.

35. Shin Y. CEO ethical leadership, ethical climate, climate strength, and collective organizational citizenship behavior. J Business Ethics 2012;108:13.

36. Bates CK, Jagsi R, Gordon LK, et al. It is time for zero tolerance for sexual harassment in academic medicine. Acad Med 2018;93:163-5.

37. Chung MP, Thang CK, Vermillion M, Fried JM, Uijtdehaage S. Exploring medical students' barriers to reporting mistreatment during clerkships: a qualitative study. Med Educ Online 2018;23:1478170.
38. Babaria P, Abedin S, Berg D, Nunez-Smith M. I'm too used to it": a longitudinal qualitative study of third year female medical students' experiences of gendered encounters in medical education. Soc Sci Med 2012;74:1013-20.

39. Picton A. Work-life balance in medical students: self-care in a culture of self-sacrifice. BMC Med Educ 2021;21:8.

40. Dyrbye LN, Massie FS Jr, Eacker A, et al. Relationship between burnout and professional conduct and attitudes among US medical students. JAMA 2010;304:1173-80.

41. Leong R, Ayoo K. Seeing medicine's hidden curriculum. CMAJ 2019;191:E920-1.

42. Hopkins J, Hedlin H, Weinacker A, Desai M. Patterns of disrespectful physician behavior at an academic medical center: implications for training, prevention, and remediation. Acad Med 2018;93:1679-85.

43. University of Alberta. Black applicants admission process. Available at: https://www.ualberta.ca/medicine/programs/md/applying-to-medicine/ before-you-apply/black-applicants.html. Accessed May 26, 2021.

44. University of Calgary Cumming School of Medicine. Black applicant admissions process. Available at: https:/cumming.ucalgary.ca/mdprogram/ future-students/black-applicant-admissions-process. Accessed May 26, 2021.

45. University of Toronto. Black student application program. Available at: https://applymd.utoronto.ca/black-student-application-program. Accessed May 26, 2021.

46. Rodriguez JE, Campbell KM, Pololi LH. Addressing disparities in academic medicine: what of the minority tax? BMC Med Educ 2015;15:6. 